\title{
Research on Chinese Corporate Social Responsibility Accounting under the Background of Low Carbon Economy
}

\author{
Zhang LiuCheng, Yin Long \\ Harbin University of Commerce, Harbin 150028, China
}

Keywords: Low carbon economy; social responsibility; social responsibility accounting; information disclosure

\begin{abstract}
In recent years, the problem of haze that has plagued our country has become more and more serious, which has seriously affected economic development and the health of the people. In order to solve environmental problems, China must transform traditional high-energy production methods and consumption patterns, and take a low-carbon economic development path. In the context of a low-carbon economy, companies are required to actively abide by the social responsibility of environmental maintenance and carry out a series of energy-saving and emission reduction activities. Based on the analysis of the connotation of corporate social responsibility in the context of low-carbon economy, this paper attempts to design a corporate social responsibility accounting system, clarifies the objectives and contents of corporate social responsibility accounting, and puts forward proposals for enterprises to effectively fulfill their social responsibilities. This will facilitate the disclosure of relevant social responsibility information of enterprises and help to improve the level of corporate social responsibility for environmental protection.
\end{abstract}

\section{Introduction}

Over the past 30 years of reform and development, China's rapid economic development has achieved remarkable results, but the environmental pollution problems that followed have become more serious. In recent years, haze weather has plagued most cities in northern China, seriously affecting China's economic development, and also has a negative impact on people's health. The problem of air pollution has become a very unstable problem in China's economic and social development. Enterprises dealing with environmental pollution should actively implement the corresponding environmental maintenance social responsibility. In 2007, China surpassed the United States to become the world's first carbon emitter. In 2011, China's carbon dioxide emissions accounted for $25.5 \%$ of the world's total carbon emissions. It still remains the world's largest emitter of greenhouse gases and environmental pollution, China's environmental problems and carbon reduction. The discharge pressure is getting more and more serious. In the past, relying on high-input, high-energy, high-carbon economic growth models is no longer suitable for the environmental reality China faces. In the new era, China should fully consider the constraints of environmental sustainability while pursuing the speed of economic development. It is imperative to develop a low-carbon economy.

In a low-carbon economy, enterprises fulfill their social responsibilities at least the following: First, ethical responsibility means that the behavior of enterprises and employees should be matched with the expectations of the society and the external ethical responsibility. Corporate business ethics, corporate integrity, and protection of the ecological environment. Second, legal responsibility, the development of a low-carbon economy is protected by law, and the operation of a company must comply with the corresponding institutional arrangements. Legal responsibility is the social responsibility that enterprises must fulfill. Under low-carbon economy, enterprises should increase the utilization ratio of clean energy. Energy applications should be subject to laws and regulations. At the same time, enterprises should reduce energy consumption in production and produce products that meet low carbon standards. Third, environmental responsibility, as environmental pollution problems become more serious, the whole society should make corresponding contributions to 
environmental improvement, and enterprises should actively fulfill their environmental maintenance responsibilities. Enterprises should actively carry out scientific and technological innovation, energy development, improve production technology level, energy structure and thus reduce energy consumption of enterprises to actively fulfill their responsibility for environmental protection. Fourth, public welfare responsibility, in the process of low-carbon economy, in addition to participating in charitable activities such as donation, charity, and assistance, enterprises must also become advocates of low-carbon environmental protection, and actively promote the promotion of low-carbon life and low-carbon consumption. Guide your customers to invest in environmental protection.

\section{Corporate social responsibility in a low-carbon economy}

The low-carbon economy is an economic development model based on reducing energy consumption, reducing emissions, and preventing pollution. It is a "win-win" economic development pattern that alleviates the conflict between ecological environment and economic development, can achieve economic development goals, and achieve environmental protection goals. . Developing a low-carbon economy is an inevitable choice for achieving sustainable economic development under the circumstance of deteriorating environmental problems. In the process of achieving low-carbon development, it is necessary not only for the state to change the economic development model from the macro level, to adjust the industrial structure, to build an ecological civilization, but also to take the road of low-carbon development from the micro level and actively assume corresponding social responsibilities. The realization of a low-carbon economy requires the joint efforts of the government, enterprises and people. The role of enterprises is the most important. As an important part of the social economy, enterprises must take into account the interests of the society while actively realizing their own economic interests. Responsibility to achieve a harmonious development of the economy and the environment.

Environmental responsibility is the most important manifestation of corporate social responsibility in the context of low-carbon economy. It requires enterprises to take into account social interests when pursuing maximum economic benefits, reduce the adverse impact on the natural environment during the production and operation process, and adopt corresponding environmental protection measures to fulfill Responsibility for environmental protection and safeguarding the public interest. In the context of low-carbon economy, corporate environmental protection responsibility becomes more and more important, and it is widely concerned by the society and the public. The environmental responsibility that enterprises need to fulfill should include the following aspects: First, reduce energy consumption and improve resource utilization. Rate, requiring enterprises to improve processes or processes in the production process, eliminate obsolete facilities, use low-energy production equipment, improve energy efficiency, and reduce unnecessary waste of resources. Second, control waste emissions, require enterprises to be in production and operation. In the process, the discharge of waste water, waste gas and waste slag is reduced, and the control is strictly controlled during the discharge process. If the standard is not up to standard, it can not be discharged, and the pollution of water quality, air and soil is reduced. Third, technological innovation, active research and development is related to business operations. Carbon reduction technology, carbon removal technology and carbon-free technology, increase the corresponding capital investment, enhance the level of independent research and development, and improve the emission reduction effect.

\section{Corporate Social Responsibility Accounting Design under Low Carbon Economy}

The emergence of a series of social problems plaguing China's smog problems and environmental pollution has led the Chinese government to implement a low-carbon development strategy. However, China's current accounting system is difficult to adapt to the accounting and supervision of corporate social responsibility in the context of low-carbon economy. In the traditional accounting system, the company's expenditures related to energy conservation and emission reduction and daily operating 
expenses are included in the cost and expense accounts, and it is difficult to accurately calculate the amount of environmental protection expenses for energy conservation and emission reduction. For the lack of effective measures for the efforts of corporate environmental protection activities, it is difficult for policy makers to make correct decisions on improving energy conservation and emission reduction responsibilities based on existing financial information, which is not conducive to long-term development of enterprises, and is not conducive to the realization of social environmental governance objectives. . To solve these problems, enterprises need to break through the traditional accounting model, establish a corporate social responsibility accounting system in a low-carbon economy, separately account for environmental maintenance responsibility accounting issues, and ultimately achieve good corporate social responsibility.

\subsection{Social responsibility accounting target}

Social responsibility accounting is to regard the relationship between business and society as social responsibility, and to confirm, measure, record and report on the social benefits and social costs. Social responsibility accounting is the product of the combination of accounting with sociology, environmental science and welfare economics. It is the result of the continuous development and extension of accounting. Corporate social responsibility accounting is carried out around the relationship between enterprises and society, mainly related to the social content of ecological environmental protection and the maintenance of employees' legitimate rights and interests. The basic goal of social responsibility accounting is to provide basic information to external information users and to provide internal management with accounting information that is conducive to making the right decisions. The ultimate goal of social responsibility accounting is to achieve a win-win situation between enterprise interests and social development, that is, the economic efficiency goal and the social benefit goal are simultaneously realized, instead of only maximizing the enterprise benefits in traditional accounting.

\subsection{Social responsibility accounting system}

China's "Accounting Standards for Business Enterprises" stipulates that corporate financial accounting mainly includes six items of assets, liabilities, owner's equity, expenses, income and profits. The issues arising from the implementation of social responsibility by enterprises are mainly divided into economic matters and non-economic matters. For example, whether the internal environmental management system of the enterprise is established, whether the internal communication mechanism for environmental protection is established, whether it is certified by the relevant environmental protection department, etc., which are not directly related to the non-economic matters of business activities and financial activities, it is difficult to conduct accounting measurement. Therefore, it is only necessary for companies to fulfill their social responsibilities and conduct regular disclosures. Economic matters include social responsibility assets, social liability liabilities, social responsibility costs, and social responsibility benefits. They must be confirmed, measured, recorded and reported according to the specific project content.

Social Responsibility Income refers to the benefits that an enterprise brings to a company due to its social responsibility. It can be divided into direct income and indirect income. Among them, direct income will generally bring certain economic benefits or economic compensation to enterprises. For example, enterprises' performance in energy conservation and emission reduction is highlighted by corresponding financial subsidies and tax reductions; the economic income obtained by enterprises selling excess carbon emission rights can be Confirmed as "social responsibility income". Indirect income The relevant honorary title obtained by a general enterprise due to its outstanding social responsibility performance, and the resulting increase in operating income and the increase in investment opportunities. Of course, since the indirect social responsibility income cannot be measured in monetary terms, it is only necessary to make a qualitative disclosure in the notes to the statement. 


\section{Proposal to effectively fulfill corporate social responsibility}

First, strengthen the system of social responsibility and enhance the sense of responsibility of enterprises. The government should formulate a set of practical social responsibility laws and regulations that are conducive to the development of low-carbon economy, strengthen supervision and management, establish a good incentive mechanism, encourage enterprises to fulfill their environmental social responsibility, and give certain rewards.

Second, establish a measurement and accounting system for social responsibility accounting to improve the standardization of social responsibility accounting. The traditional accounting system can no longer meet the needs of the new era. Relevant research institutions and accounting organizations should formulate accounting standards and systems related to corporate social responsibility, so that the measurement and accounting of corporate social responsibility is more standardized and standard. Through the social responsibility accounting system, the enterprise can reasonably confirm and measure the relationship between the business process and the environment, realize the quantitative reflection of relevant information, and effectively present the true level of corporate social responsibility.

Third, improve the corporate social responsibility information disclosure and supervision mechanism to ensure the effectiveness of corporate social responsibility information. Clarify the requirements for corporate social responsibility information disclosure, standardize the content of corporate social responsibility information disclosure, establish an effective corporate social responsibility reporting system, strengthen the process of information disclosure, ensure the authenticity and validity of disclosure information, and avoid false information. To improve the comparability and practicability of disclosure information is conducive to the comparative analysis of the performance of relevant corporate social responsibility by policy makers. Strengthen supervision, formulate a reasonable reward and punishment mechanism, carry out certain material rewards for enterprises with complete information disclosure, and impose corresponding economic punishments on enterprises that publish false information, which is beneficial to fully mobilize the enthusiasm of enterprises to disclose information, and is also conducive to promotion. The authenticity of the information disclosed by the company.

\section{Acknowledgment}

This work is supported by Heilongjiang Provincial Social Science Fund Project "Research on the Construction of Heilongjiang Province Financial Sharing Platform Based on the Perspective of Blockchain Technology" (18JYE672).

\section{References}

[1] Zhang Liucheng.Application-oriented Institutes Innovation Thinking and Practice of Talent Training Mode[J]. Advances in Social Science, Education and Humanities Research, 2016(59), pp. $1425-1429$

[2] Zhang Liucheng.Analysis on the future development of cloud Education[J]. Advances in Social Science, Education and Humanities Research,2016 (59) , pp. 1477-1480

[3] Zhang Liucheng.Research on the construction of education service platform based on Cloud Computing[J]. Advances in Social Science, Education and Humanities Research, 2016 (59), pp. 1481-1484

[4] Zhang Liucheng.Application Prospect of Block Chain Technology in Accounting Industry,2018 International Conference on Mechatronics Engineering and Computer Sciences(ICMECS 2018). IEEE, 2018:559-562.

[5] Zhang Liucheng,Chen Meizhi. The analysis of the deep processing industry of agricultural products and strategy in Heilongjiang Province,2018 International Conference on Mechatronics Engineering and Computer Sciences(ICMECS 2018). IEEE， 2018:568-572. 